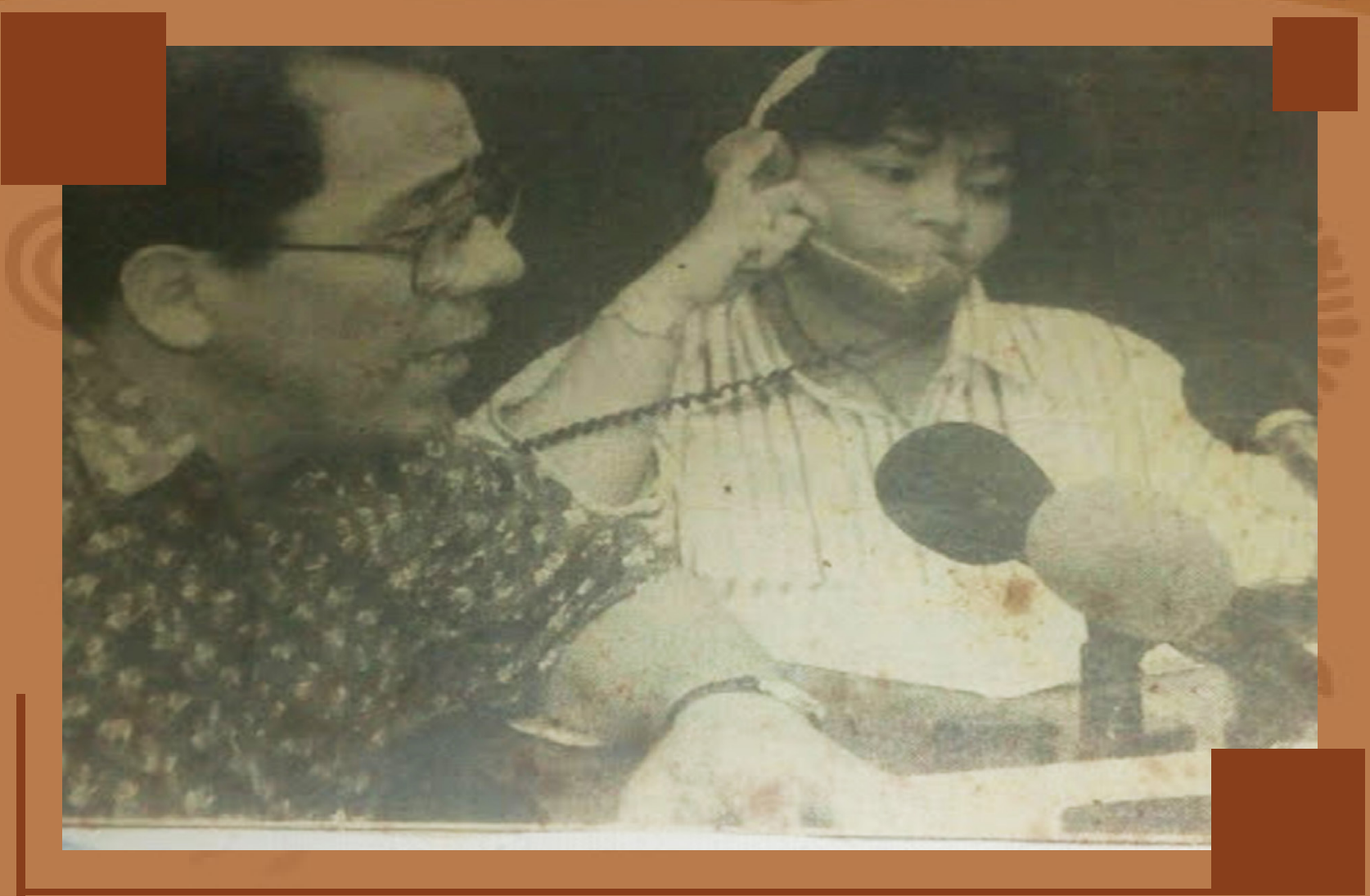

La historia oral como método y metodología para el estudio del periodismo radiofónico y la libertad de expresión en la región histórica de Managua 1936-1979

Estudios Interdiciplinarios 


\section{La historia oral como método y metodología para el estudio del periodismo radiofónico y la libertad de expresión en la región histórica de Managua 1936-1979}

\section{Oral history as a method and methodology for the study of radio journalism and freedom of expression in the historic region of Managua 1936-1979}

Walter Jerónimo Calderón Ramírez

Recibido: 11-11-2019

Comunicación para el Desarrollo

Universidad Nacional Autónoma de Nicaragua

ID Orcid: https://orcid.org/0000-0002-6896-3554

wjcalderon@gmail.com

\section{Resumen}

Este artículo aborda la metodología para el estudio del "Periodismo Radiofónico y Libertad de Expresión en la región de Managua, en el período 1936-1979”, como parte de la investigación homónima de tesis del autor como parte del Doctorado en Historia con Mención en Estudios Regionales y Locales Transdisciplinarios. El objeto de estudio será analizado desde el enfoque de la historia oral como método, metodología y como técnica para comprender cómo evolucionó la comprensión del derecho a la libertad de expresión en tres emisoras de la región de Managua (Radio La Voz de la América Central, Radio Mundial y Radio Corporación) en un contexto marcado por el ascenso, apogeo y derrocamiento de la dictadura somocista. Con ello se pretende aportar a recuperar las percepciones, voces y miradas desde la memoria tanto de los periodistas y trabajadores de la radio como de las personas adultas mayores que participaron en su calidad de oyentes. El resultado de la investigación es un proceso de reconstrucción histórica de dichos acontecimientos relacionados con las subjetividades políticas y desde las personas que estuvieron directamente involucradas en estos procesos, para rescatar el recorrido vivido a través del relato oral como fuente de ese pasado vivido.

Palabras claves: Metodología, historia oral, radiodifusión, libertad de expresión, periodismo, estudios regionales, Managua, Nicaragua.

\section{Abstract}

This article deals with the methodology for the study of "Radio Journalism and Freedom of Expression in the Managua region, in the period 1936-1979", as part of the author's thesis research as part of the Doctorate in History with a Mention in Studies Regional and Local Transdisciplinary. The object of study will be analyzed from the oral history approach as a method, methodology and as a technique to understand how the understanding of the right to freedom of expression evolved in three stations in the Managua region (Radio La Voz de la América Central, World Radio and Radio Corporation) in a context marked by the rise, heyday and overthrow of the Somocista dictatorship. This is intended to help recover the perceptions, voices and glances from the memory of both journalists and radio workers as well as the elderly who participated in their capacity as listeners. The result of the investigation is a process of historical reconstruction of these events related to political subjectivities and from the people who were directly involved in these processes, to rescue the journey lived through the oral story as a source of that lived past.

Keywords: Methodology, oral history, broadcasting, freedom of expression, journalism, regional studies, Managua, Nicaragua. 


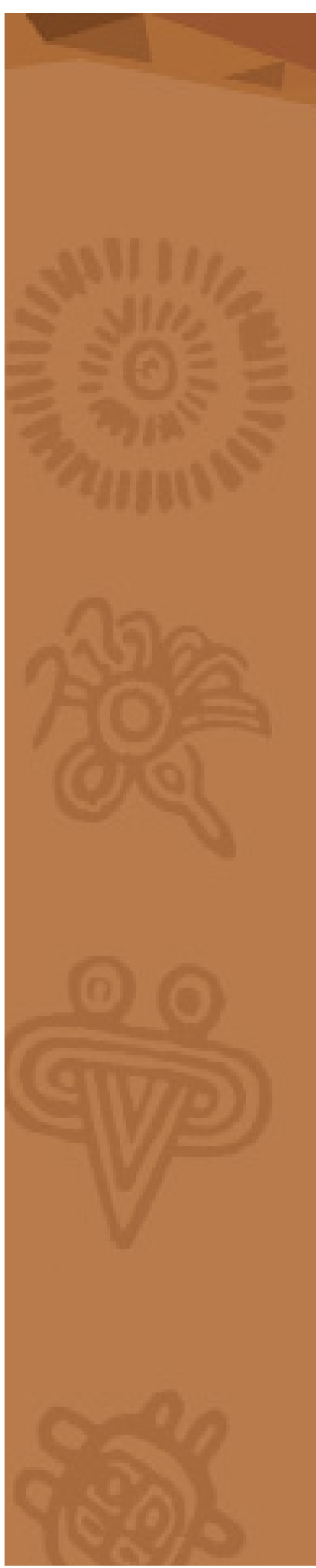

\section{Introducción}

Este artículo, es una revisión de avance de investigación. El autor examina el proceso de estudio del "Periodismo radiofónico y libertad de expresión en la región de Managua 1936-1979”. El propósito de la investigación es analizar los derechos, deberes y restricciones a la libertad de expresión (entendida como una categoría de análisis histórico, puesto que cada época tiene su propia caracterización y concepción de la libertad de expresión) en el campo del periodismo radiofónico en la región de Managua en el período 1936-1979. El enfoque de esta investigación se realiza desde la perspectiva de los estudios históricos regionales y locales transdisciplinarios para comprender cómo se vinculó el derecho a la libertad de expresión e información en el periodismo radiofónico de región de Managua.

En este sentido la principal característica del presente estudio es la adopción de la historia oral como método, como metodología y como técnica de análisis. Al utilizar la historia oral esta investigación se interesa no solamente por lo que puedan decir las fuentes orales, sino también sus silencios, los olvidos y el valor metafórico de la verdad, el cual contiene algunos errores o distorsiones en el relato (Coira, 2008).

Con ello este estudio aporta a construir como fuentes orales a las personas que contribuyeron a la creación y desarrollo del periodismo radiofónico en el período 1936-1979, el cual coincide con el ascenso, apogeo y caída de la dictadura somocista. De igual manera, interesa consultar como fuentes a manera a las personas adultas mayores que escucharon la programación de estas emisoras y que pueden dar cuenta desde sus percepciones acerca de cómo comprendían y vinculaban su derecho a la libertad de expresión a la labor realizada por el periodismo radiofónico. Por lo cual se hace importante poder darles voz, reconocer sus aportes, conocer sus visiones y percepciones sobre lo vivido, ya que, de no mediar esta tarea, sus testimonios estarían condenados al olvido y desaparición. Al mismo tiempo con ello se pretende contribuir a las posibilidades de analizar a partir de este trabajo la radio como fenómeno comunicacional regional y local.

Este es precisamente uno de los grandes aportes de la historia oral como método de investigación interdisciplinario "ya que destaca y centra su análisis en la visión y versión de lo más profundo de la experiencia, expresan los sujetos sociales considerados centralmente en el ámbito de la historia social-local-oral" (Aceves, 1998, pág. 210).

Al mismo tiempo se ha reconocido a la historia oral como innovadora, tanto en su objeto de estudio como por dar atención a los "dominados"; es decir aquellos personajes tradicionalmente excluidos de la historia (mujeres, obreros, marginados); de igual manera porque presta atención a lo cotidiano y la vida privada. La historia oral ha sido también considerada como una historia desde abajo, es decir enfocada en las formas de ver y sentir, por lo cual marca una ruptura epistemológica con el positivismo, al dar atención a la visión subjetiva en una perspectiva micro-histórica (François, 2006). 


\section{Desarrollo}

El reconocimiento tardío de la historia oral como método válido y legítimo para el estudio de la historia, se debe a la existencia de un sector académico que ve con recelos provenientes del positivismo.

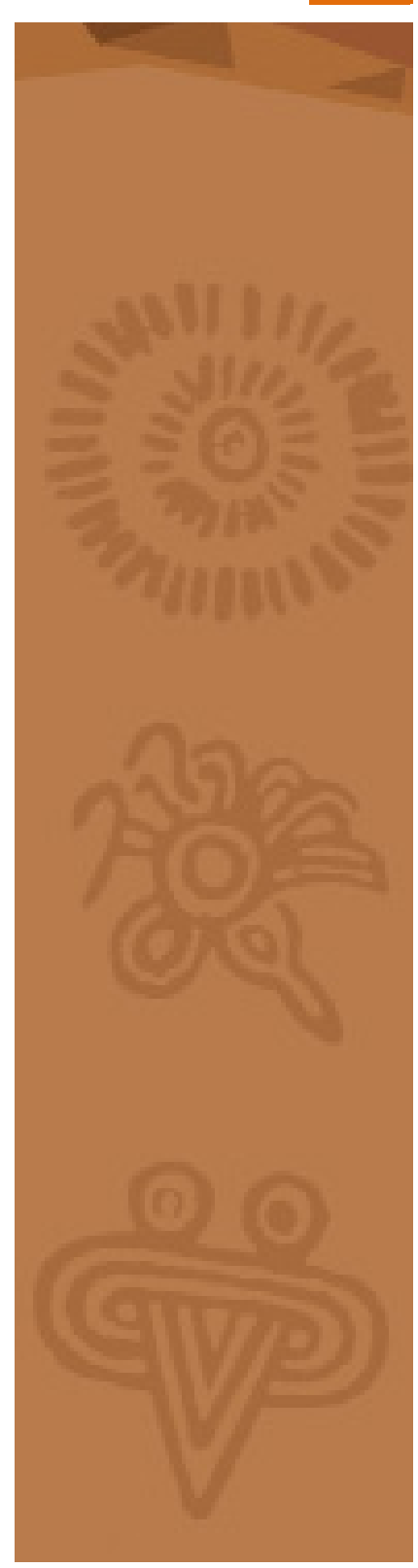

Frente a las críticas del positivismo con respecto a la subjetividad de la historia oral, es preciso tomar en cuenta a Toulmin (Citado por Barona, 1994) quien considera que la ciencia no puede ser considerada como un mero conjunto de hechos empíricos aislados, que esperan ser descubiertos por el hombre, sino que es ciencia también la forma como el hombre percibe e interpreta esos hechos a través de una explicación racional e integradora. En este sentido, lo más importante es determinar en cada caso la relación entre la teoría y los hechos, el modo como los datos empíricos dan validez o hacen variar los contenidos de una teoría científica.

En este contexto, se acepta que con la introducción de la física cuántica de Einstein y el principio de incertidumbre de Heisenberg, se afirma que el sujeto del proceso del conocimiento infiere sobre el objeto de estudio, y que las verdades que podemos conocer científicamente son aproximativas, condicionadas por el observador y las circunstancias, es decir, por aspectos internos, -subjetivos, de la propia comunidad de especialistas-, y externos, -de la sociedad y la política-. Hablamos, pues, de una ciencia con sujeto, no solamente con objeto, porque no es científico separar objeto y sujeto en el proceso de conocimiento. La historia, en este marco, se configura como una ciencia con conciencia, porque, en definitiva, se trata de no contraponer la objetividad con la subjetividad, sino de compaginarlas en una relación dialéctica (Agulló, 2010).

El reconocimiento tardío de la historia oral como método válido y legítimo para el estudio de la historia, se debe a la existencia de un sector académico que ve con recelos provenientes del positivismo, los usos de la historia oral, pues para ellos el pasado constituye una realidad objetiva y objetivable. De tal manera que el trabajo del historiador, desde el enfoque positivista fue visto como una reconstrucción fiel de los hechos del pasado de acuerdo a los acontecimientos. Por tanto se establecían restricciones para que el historiador interpretara o evaluara los acontecimientos del pasado o incluso establecer comparaciones o relaciones con el presente o el futuro (Barona, 1994, pág. 49).

Justamente las nuevas corrientes historiográficas aceptan que el conocimiento histórico no puede ser construido en base a la objetividad. A comienzos del S. XX historiadores como Carl Becker y Charles Beard, enfatizaron sobre la relatividad del conocimiento histórico localizado en un contexto temporal concreto y sujeto al cambio al mismo tiempo (Aurell \& Burke, 2013, págs. 241242). En este contexto es que poco a poco la historia oral va ganando terreno y especialmente a mediados del S. XX, utilizada primeramente como una técnica de la corriente llamada "historia social" y que emerge, sin pretensiones de sustituir otro tipo de fuentes, ni tampoco comenzar una nueva discusión teórica. Con el uso de la historia oral se generaron cambios en cuanto a la orientación democratizante del género histórico, especialmente para dar voz a los actores sociales en un primer plano del relato científico, con lo cual se restó protagonismo a los autores del texto historiográfico (Hernández, 2004). 
La historia oral ha sido considerada como un método legítimo de estudio, la cual es utilizada de forma interdisciplinaria para muy variados propósitos y objetos de estudio.

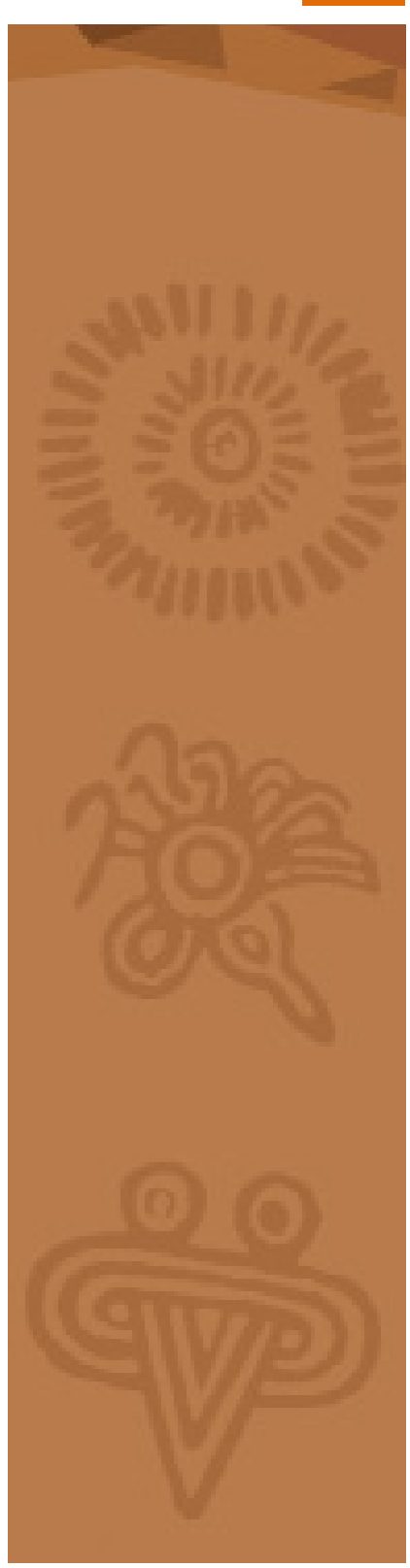

En la actualidad la historia oral ha sido considerada como un método legítimo de estudio, la cual es utilizada de forma interdisciplinaria para muy variados propósitos y objetos de estudio. En México por ejemplo, uno de los países latinoamericanos con una vasta experiencia y trayectoria que ha trabajado bajo este enfoque, la historia oral ha alcanzado un gran nivel de profesionalismo se han abierto espacios de intercambio y estudio, trayendo una amplia bibliografía y publicación de revistas sobre este ámbito (Aguirre, 1998, pág. 12; Mayer, 1995).

En Nicaragua, la historia oral ofrece la oportunidad a sus ciudadanos de reconocer y recuperar tanto la historia, como la herencia cultural; que contribuya a explicarla y que permita a la sociedad conocer mejor su pasado, pues como dice Pierre Vilar "hay que comprender el pasado, para conocer el presente" (Vilar, 1980, pág. 12). De hecho, en los últimos 30 años como parte de las políticas de memoria, Nicaragua demostró sus potencialidades al recuperar y construir una nueva identidad nacional articulada alrededor de los valores del sandinismo.

Un aporte fundamental fue el trabajo tesonero realizado por diversos historiadores e investigadores quienes emprendieron proyectos nacionales de historia oral, por medio de los cuales recuperaron el testimonio y las voces de miles de ciudadanos involucrados en la insurrección, la lucha contra la dictadura somocista, así como combatientes, dirigentes, sobrevivientes del Ejército Defensor de la Soberanía Nacional, así como madres de héroes y mártires de la revolución (Vannini, 2014, págs. 76-77).

En la actualidad se reconoce que la historia oral ha abandonado su condición de marginalidad académica, y reconocimiento casi suplicante, así como las confrontaciones de otras épocas y ha buscado nuevas sendas y posibilidades poco exploradas como los problemas de actores sociales en contextos urbanos, causas y consecuencias del subdesarrollo, migraciones, pobreza así como la violencia generacional, genérica o sectores tradicionalmente excluidos como niños y jóvenes que buscan autoconstruir sus propios discursos históricos (Mayer, 1995, pág. 99).

La historia oral posee una larga y prestigiosa historia que en ocasiones ha sido denostada. Sin embargo, como reconocen Brunschwig \& Lloyd (2000, pág. 284) la historia oral está presente como método de trabajo de los padres de la historia como Herodoto y Tucídides, en una época donde acceder a las fuentes documentales era muy escasa. Sin embargo fue en el S. XX cuando los historiadores dejaron a un lado la historia oral y se concentraron únicamente en el estudio crítico de las fuentes escritas (Schwarzstein, 2001)

En el caso particular de América Latina, la historia oral ha estado presente en los procesos de redemocratización, especialmente en aquellos países que sufrieron las consecuencias de dictaduras militares y políticas apoyadas por Estados Unidos. Por tanto a diferencia de los caminos tomados por la historia oral en Europa y Estados Unidos, en el caso particu- 


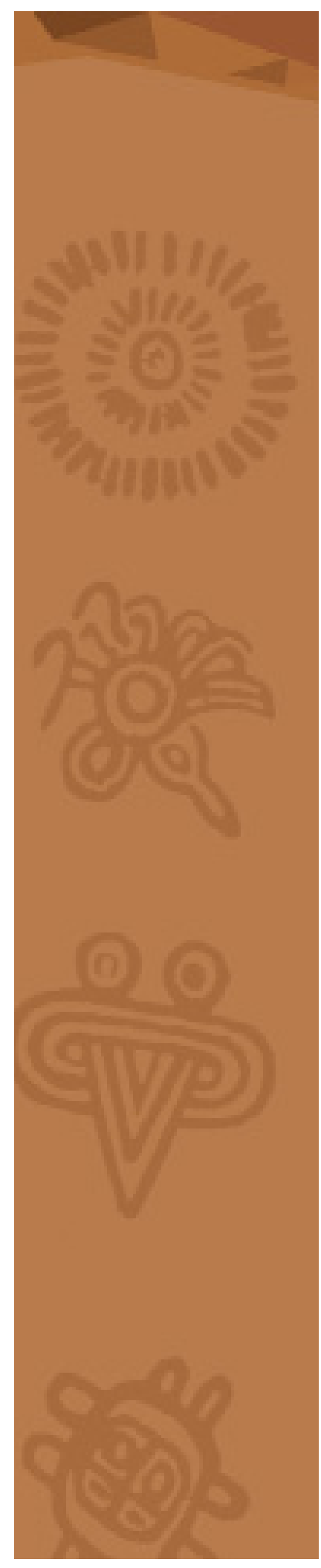

lar de América Latina, la historia oral se colocó en un escenario político de redefinición democrática, para comprender la sociedad, especialmente ante el agotamiento de modelos teóricos conservadores, tradicionales e insuficientes para apuntar alternativas de políticas públicas (Sebe, 2000, pág. 86).

Estos procesos de violencia hegemónica en contra de la clase trabajadora, movimientos populares y proyectos revolucionarios, plantean el reto para el investigador al considerar el contexto de cruenta represión política y social, la cual limitó de alguna forma la producción de documentos que registren las ideas, decisiones y discusiones políticas, muchas de las cuales especialmente cuando fueron contestarías o cuestionadoras del poder, fueron destruidas (Pozzi \& Pérez, 2012). Con lo cual el proceso de reconstrucción de dichos acontecimientos está relacionado directamente con las subjetividades políticas y desde las personas que estuvieron directamente involucradas en estos procesos, para rescatar el recorrido vivido a través del relato oral como fuente de ese pasado vivido.

Precisamente para recuperar la memoria, es que se utiliza la entrevista como método de la historia oral, las cuales se realizan con fuentes orales, entendiendo que estas fuentes son una construcción artificial y consciente. Las fuentes orales, como señala (Benadiba \& Plotinsky, 2005) presentes características específicas, tanto por su contenido, como por los problemas que se derivan de la subjetividad de la memoria, las que en etapas sucesivas deben ser trabajadas para su uso.

Se debe tomar en cuenta que estas fuentes orales, dependen de las habilidades de en buena medida del investigador. Es decir de su capacidad de saber elaborar las preguntas, de establecer diálogo, así como del rapport para crear una relación personal con sus entrevistados. Hay que tener presente como explica Schwartsztein (Citado por Benadiba \& Plotinsky, 2005) además que las fuentes son únicamente instrumentos para elaborar la historia, es decir ni los documentos que se encuentran en los archivos son la historia, ni tampoco las entrevistas por más ricas e interesantes que éstas sean.

El instrumento que se privilegia para recuperar el testimonio de las personas que se involucraron ya sea como profesionales/ trabajadores de la radio u audiencia de dichas emisoras, es la entrevista considerada como una innovación dentro de la historia oral, puesto que esto permite reunir evidencias en el trabajo de campo (Thompson, 1988). En este sentido Thompson considera que los historiadores no son puristas metodológicos, sino urracas; ante un problema, se apoderarán de cualquier evidencia que puedan descubrir y le darán el mejor uso posible. Este autor advierte además que la evidencia resultará parchada y sesgada, y que cuanto más remoto sea el período estudiado, más inadecuada tenderá a ser. 
La entrevista de historia oral ha sido definida como una"narrativa conversacional".

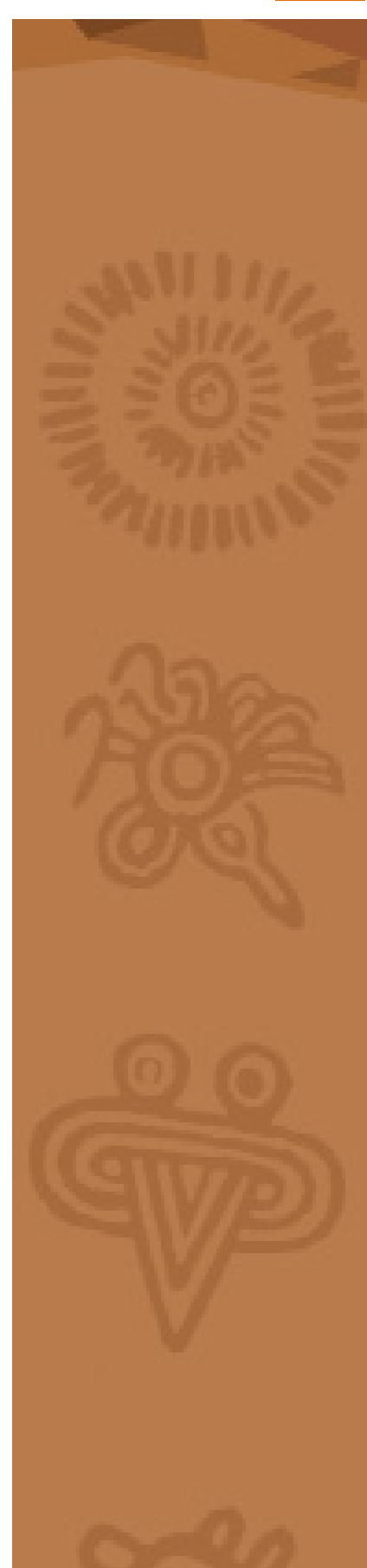

La entrevista de historia oral ha sido definida como una "narrativa conversacional". Se dice que es conversacional por la relación que se establece entre entrevistado y entrevistador, y narrativa por la forma de exposición -en que "se cuenta, relata o narra una historia” (Grele, Citado por Educ.ar, s/f). Se trata de un diálogo con mayor profundidad y complejidad que el de una conversación cotidiana, pero con una relación de confianza entre entrevistado y entrevistador.

Como advierte Benadiba (2012) cuando se realiza una entrevista las personas recuerdan desde su propia experiencia personal e individual, pero su testimonio está basado en la interacción con los otros. En consecuencia, además de las memorias individuales, las sociedades tienen una memoria colectiva transmitida oralmente o por medio de textos, conmemoraciones o monumentos, "que se basa en lo que nos contaron nuestros abuelos, maestros, en lo que aprendimos por medio de los libros, en los documentos que se conservan en los archivos, en lo que nos transmiten los medios de comunicación o en lo que nos imponen desde el poder".

Al mismo tiempo es preciso tomar en cuenta que el historiador oral debe estar consciente que el entrevistado es un representante de la cultura, con una visión particular e individual del mundo, formado dentro de la cultura hegemónica o en oposición a dicha ideología. En otras palabras, es como si los testimonios fueran una combinación de mito e ideología. De ahí que los testimonios orales deriven de la esfera subjetiva, ubicada dentro de la actividad simbólica vinculada con lo psicológico, cultural y cognitivo. Esto implica que en el proceso de entrevista, el que pregunta debe estar atento al qué se dice, a través de lo que permiten las convenciones de la conversación socialmente ordinaria (lealtades invisibles) y los significados de lo que se dice (de Garay, 1999).

Grele (Citado por James, 2004) sostiene además que en la entrevista oral hay una tensión fundamental entre el relato y el análisis, puesto que, si se acepta que la historia oral es un relato basado en conversaciones, esa conversación suele producirse en oposición al poder de la narrativa... "Mientras destruimos como tal, el entrevistado trata rápidamente de restablecerlo... el papel del entrevistador es crucial, pero lo ejercemos agregando detalles, forzando la memoria hasta sus límites, destruyendo su propia capacidad narrativa. No lo tratamos como una historia que sigue desenvolviéndose y nos lleva consigo, sino como un objeto de análisis y deconstrucción”.

El hecho de que el informante incurra en inexactitudes no implica que su testimonio no sea fiable, sino que el material recabado hay que analizarlo de cara a su ponderación, dentro del contexto de su propia experiencia, percepción y recorrido personal. Así se refiere al respecto Schwarzstein (2001) al considerar que la memoria “...no es una narración literal o fotográfica de los hechos históricos sino evocación, ideas de la persona y deseos inconscientes. Sin duda la memoria tiene un carácter subjetivo y tendencia a interpretar la historia más que a reflejarla. Esto no apun- 


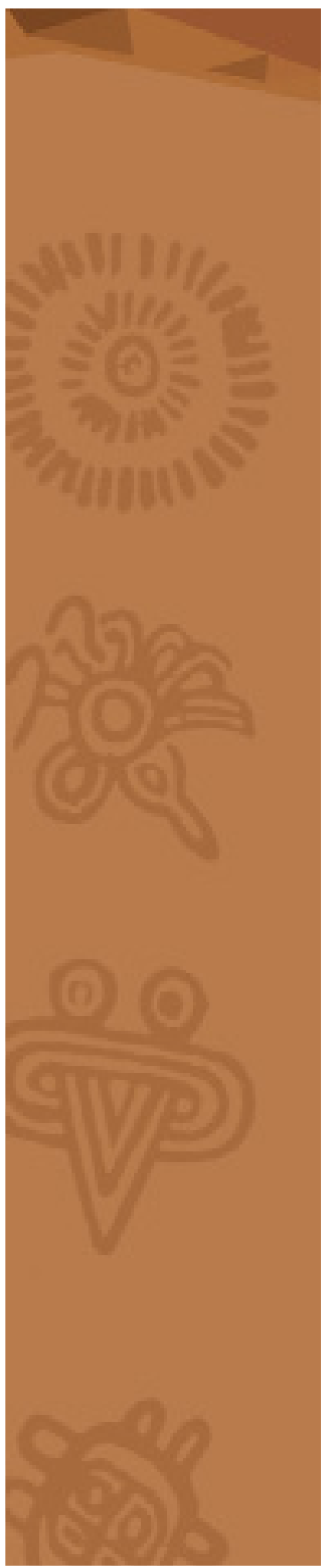

ta a la no-fiabilidad de la memoria como fuente histórica, sino que da cuenta de la complejidad y riqueza de la experiencia humana". En este sentido las entrevistas permiten recuperar singularidades inimaginadas. Ayudan a comprender que todos somos parte de la historia de una comunidad, y que toda experiencia puede interesar al conocimiento histórico.

Los relatos orales obtenidos en las entrevistas son artefactos particularmente favorables para el aprendizaje de la historia y posibilitan el desarrollo de habilidades para la indagación. Permiten por otra parte relacionar la historia con el accionar de personas concretas y recuperar en la enseñanza aspectos relativos al modo de construcción del conocimiento histórico. Lo aconsejable es un reiterado camino de ida y vuelta entre lo particular y lo general, respetando los ritmos y modalidades de ambas esferas.

Para la realización de este trabajo se realizarán 10 entrevistas (trabajadores de la radiodifusión en el período estudiado), las cuales darán como resultado igual número de entrevistas. Estas entrevistas tomaran forma de historias de vida y trayectorias vitales. De forma particular, esta investigación atiende con particular interés las historias de vida para entender como los individuos están inmersos en redes de relaciones sociales, algunas creadas por ellos y otras que son independientes de su voluntad y sus actos. Es por ello que desde la historia oral, se estudian esas relaciones sociales en diferentes escenarios: trabajo, familia y comunidad fin de obtener un relato en el que se relatan tanto los triunfos como los fallos, los infortunios y conflictos para comprender la trayectoria vital (Necoechea, 2000).

Los criterios que guían la selección de los informantes claves apuntan a obtener una muestra representativa adultos mayores, los cuales participaron como trabajadores de espacios informativos de tres emisoras (Radio La Voz de la América Central, Radio Mundial y Radio Corporación) de la región de Managua en el período 1936-1979, así como en su calidad de oyentes de la programación de dichas emisoras.

Al mismo tiempo se espera poder realizar cruces entre fuentes orales y escritas, las cuales serán de particular utilidad, especialmente para verificar la calidad de la información obtenida. En primer lugar, las fuentes obtenidas de forma oral, va a permitir desarrollar nuevas interrogantes y lecturas. En este sentido se espera realizar entrevista con preguntas abiertas para no influir sobre las respuestas y tratando en lo posible de mantener un lenguaje sencillo con respecto al interlocutor. Se utilizará al mismo tiempo un cuaderno de campo, para bosquejar el contexto de vida de las personas entrevistadas y realizar anotaciones sobre aspectos que no deben ser pasados por alto como los silencios, molestias o confusión de datos o fechas, por ejemplo.

Se elaborarán al mismo tiempo la guía de entrevistas que serán utilizadas con los informantes claves. Al mismo tiempo se establecerán coordinaciones con las personas seleccionadas para acordar los días y horas en que se realizarán las entrevistas. Las entrevistas serán registradas mediante grabaciones, para lo cual se solicitará la autorización 
Cuanto más tiempo ha transcurrido, los testigos parecen estar más dispuestos a ofrecer una visión autentica de los episodios vividos.

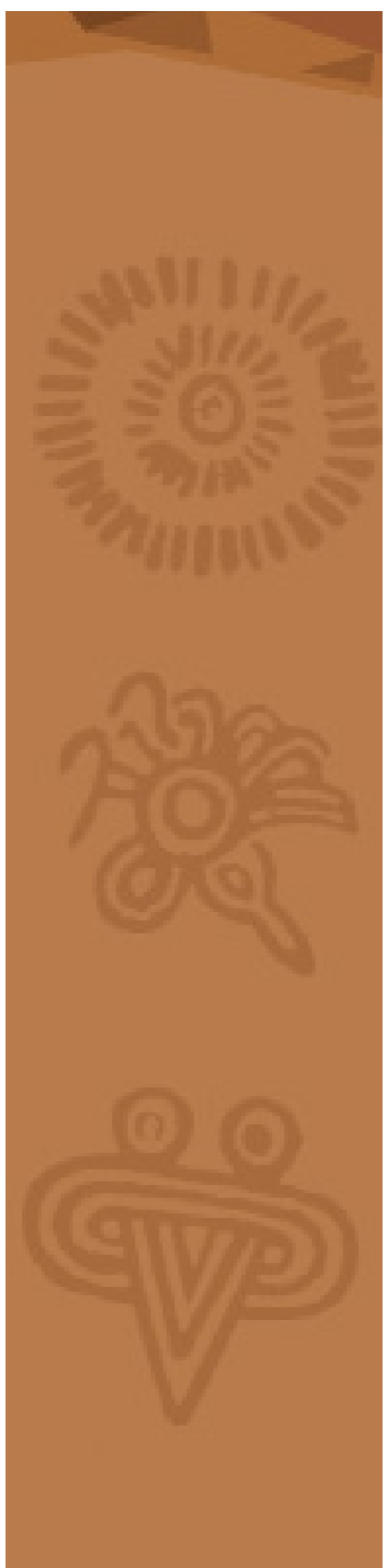

de los entrevistados. Con estas entrevistas se procederá a organizar un archivo digital en el cual se organicen las entrevistas de las fuentes orales por nombre y apellidos, día y hora. Esto será de gran utilidad especialmente para realizar las transcripciones de las entrevistas. Las transcripciones de las entrevistas serán literales, con el fin de no alterar lo dicho por los informantes, ni agregar aquello que no dijo.

La entrevista constituye una experiencia única, en la que está en juego la posibilidad de acrecentar el conocimiento histórico. La riqueza de estas entrevistas reside en que mediante ellas se espera obtener información sobre aspectos que no se conseguirían por medio de otras fuentes. Mediante la realización de estas entrevistas se espera obtener una mayor comprensión del significado personal que los trabajadores/profesionales de la radio le concedieron al tema de libertad de expresión y las consecuencias que se derivaron tanto a nivel personal como colectivo.

Estos testimonios orales nos permitirán conocer la actuación de cada uno de los entrevistados, pero también de qué modo valoran e interpretan su intervención en los hechos históricos relacionados con la lucha por la libertad de expresión en el período 1936-1979. En este sentido se ha señalado que las fuentes orales poseen una clase de veracidad que no es fácil encontrar en otras fuentes históricas, ya que permiten aproximarse a la capacidad de respuesta y expresión del individuo frente a los sucesos en los que ha participado. A pesar de esto, aun cuando los recuerdos del entrevistado no se corresponden con los acontecimientos, este hecho tiene en sí mismo un valor histórico. "La credibilidad especifica de las fuentes orales consiste en el hecho de que, aunque no correspondan a los hechos, las discrepancias y errores en sí mismos, son signos reveladores que remiten al tiempo del deseo y el dolor y a la difícil búsqueda de sentido" (Portelli, 2003).

Esta clase de material histórico ofrece aristas sumamente complejas en las que intervienen los intereses concretos del historiador: su sola presencia y las preguntas que realiza influyen en la narración de quien decide contar sus recuerdos. Contar una historia no es una simple repetición; cuando el entrevistado habla sobre su vida, al revisar su pasado interpreta, selecciona, omite, juzga. En otras palabras, pone en juego su subjetividad, otorga un sentido a los hechos recordados.

Sin embargo, en la mayoría de casos, en el transcurso de una entrevista no surgen recuerdos inexistentes, el proceso de recordar se organiza en torno a un núcleo de memoria, un núcleo de sentido conformado por hechos del pasado que en alguna medida conservan su percepción primera. A su vez, cuanto más tiempo ha transcurrido, los testigos parecen estar más dispuestos a ofrecer una visión autentica de los episodios vividos. En estos casos, la distancia temporal, lejos de ser un obstáculo, actúa favorablemente por cuanto la fuente oral no siente la presión de la contemporaneidad del contexto sociopolítico de la historia (Scoufalos, 2007). 


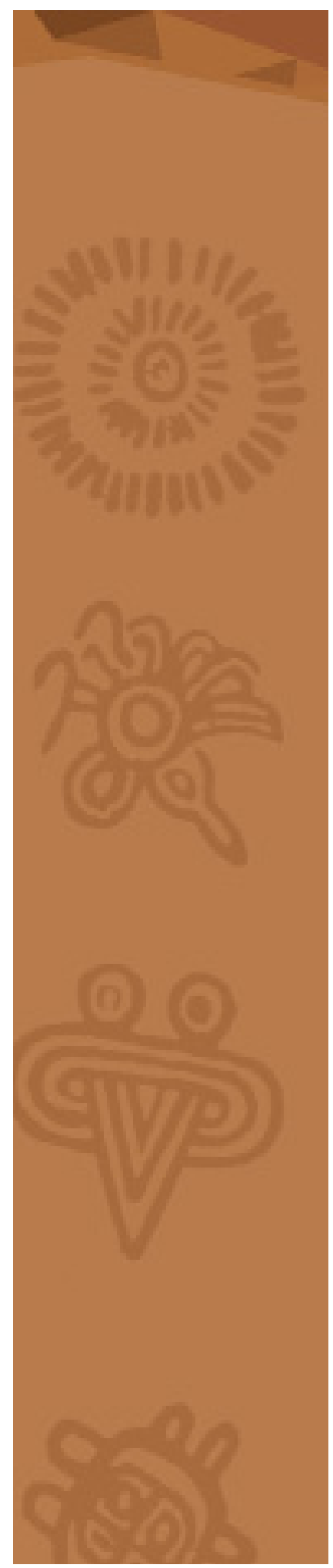

En esta investigación al mismo tiempo se busca complementar la información obtenida mediante la historia oral con otras fuentes históricas (ya sean bibliográficas, electrónicas, iconográficas, de archivo y de hemeroteca) para integrarlas y contrastarlas.

Se impone de esta forma la interdisciplinariedad metodológica. Esta es otra de las herramientas metodológicas de los historiadores. La creación de conocimiento incluye un abierto episteme que le permita navegar, innovar, crear y hacer arte de forma permanente. No hay ciencia más interdisciplinar que la historia misma en su función investigativa (Ramírez, 2010). Esta característica se debe a que como el objeto de estudio de la historia es la comprensión del pasado, los historiadores están llamados a recoger todos los vestigios que deja el hombre en su transcurrir histórico, y también los llamados a innovar en sus técnicas y teorías para realmente lograr entender ese pasado. La historia trabaja desde el paradigma de la interdisciplinariedad, lo cual ha quedado evidente en corrientes como el historicismo, marxismo y la Escuela de los Annales. La historia se construyó a partir de una episteme interdisciplinar proveniente de la filología, la hermenéutica, la filosofía, economía y política. Es por ello que Lucien Febvre señaló que el trabajo del historiador es la frontera, "con un pie aquí y otro allá".

\section{Conclusiones}

La presente investigación denominada "Periodismo radiofónico y libertad de expresión en la región de Managua 1936-1972" adopta como principal enfoque la historia oral como método, como metodología y como técnica de análisis. Al utilizar la historia oral esta investigación se interesa no solamente por lo que puedan decir las fuentes orales, sino también por sus silencios, los olvidos y el valor metafórico de la verdad, el cual contiene algunos errores o distorsiones en el relato (Coira, 2008).

El estudio pretende construir como fuentes orales a las personas que contribuyeron a la creación y desarrollo del periodismo radiofónico en el período 1936-1979, el cual coincide con el ascenso, apogeo y caída de la dictadura somocista. Es decir, a todos aquellos trabajadores que fueron parte de la programación informativa de estas emisoras y que pueden dar cuenta desde sus percepciones acerca de cómo comprendían y vinculaban su derecho a la libertad de expresión a la labor realizada por el periodismo radiofónico.

A pesar de las críticas de los historiadores que utilizan como principal enfoque el positivismo, las nuevas corrientes historiográficas aceptan que el conocimiento histórico no puede ser construido en base a la objetividad. Autores como Carl Becker y Charles Beard, enfatizan sobre la relatividad del conocimiento histórico localizado en un contexto temporal concreto y sujeto al cambio al mismo tiempo (Aurell \& Burke, 2013, págs. 241- 


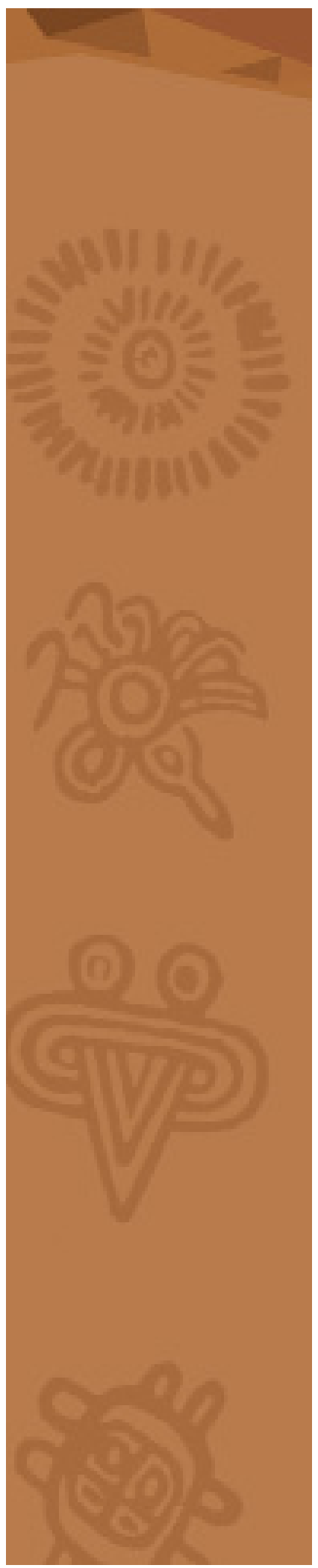

242). En este contexto es que poco a poco la historia oral va ganando terreno y especialmente a mediados del S. XX, utilizada primeramente como una técnica de la corriente llamada "historia social" y que emerge, sin pretensiones de sustituir otro tipo de fuentes, ni tampoco comenzar una nueva discusión teórica. Con el uso de la historia oral se generaron cambios en cuanto a la orientación democratizante del género histórico, especialmente para dar voz a los actores sociales en un primer plano del relato científico, con lo cual se restó protagonismo a los autores del texto historiográfico (Hernández, 2004).

Precisamente para recuperar la memoria, es que se utiliza la entrevista como método de la historia oral, las cuales se realizan con fuentes orales, entendiendo que estas fuentes son una construcción artificial y consciente. Las fuentes orales, como señala (Benadiba \& Plotinsky, 2005) presentes características específicas, tanto por su contenido, como por los problemas que se derivan de la subjetividad de la memoria, las que en etapas sucesivas deben ser trabajadas para su uso. La recolección de los datos se realizará a partir de la realización 10 entrevistas (trabajadores de la radiodifusión del período estudiado), con informantes claves. Estas entrevistas tomaran forma de historias de vida y trayectorias vitales de las personas consultadas.

De forma particular, esta investigación atiende con particular interés las historias de vida para entender como los individuos están inmersos en redes de relaciones sociales, algunas creadas por ellos y otras que son independientes de su voluntad y sus actos. Es por ello que desde la historia oral, se estudian esas relaciones sociales en diferentes escenarios: trabajo, familia y comunidad fin de obtener un relato en el que se relatan tanto los triunfos como los fallos, los infortunios y conflictos para comprender la trayectoria vital (Necoechea, 2000).

Al mismo tiempo se espera poder realizar cruces entre fuentes orales y escritas, las cuales serán de particular utilidad, especialmente para verificar la calidad de la información obtenida. Estos testimonios orales nos permitirán conocer la actuación de cada uno de los entrevistados, pero también de qué modo valoran e interpretan su intervención en los hechos históricos relacionados con la lucha por la libertad de expresión en el período 1936-1979.

\section{Bibliografía}

Aceves, J. (1998). La historia oral y de vida: del recurso técnico a la experiencia de investigación. En L. Galindo, Técnicas de investigación en sociedad, cultura y comunicación (págs. 207-265). México: Addison Wesley Longman.

Aguirre, M. E. (1998). Tramas y espejos. Los constructores de historia de la educación. México D.F. : Plaza y Valdés Editores- Universidad Nacional Autónoma de México.

Agulló, M. (2010). La voz y la palabra de los tesoros vivos: fuentes orales y recuperación del patrimonio histórico-educativo inmaterial. Vol. 28(2). Obtenido de Educatio Siglo XXI: http://revistas.um.es/educatio/article/ view/112011/106331 


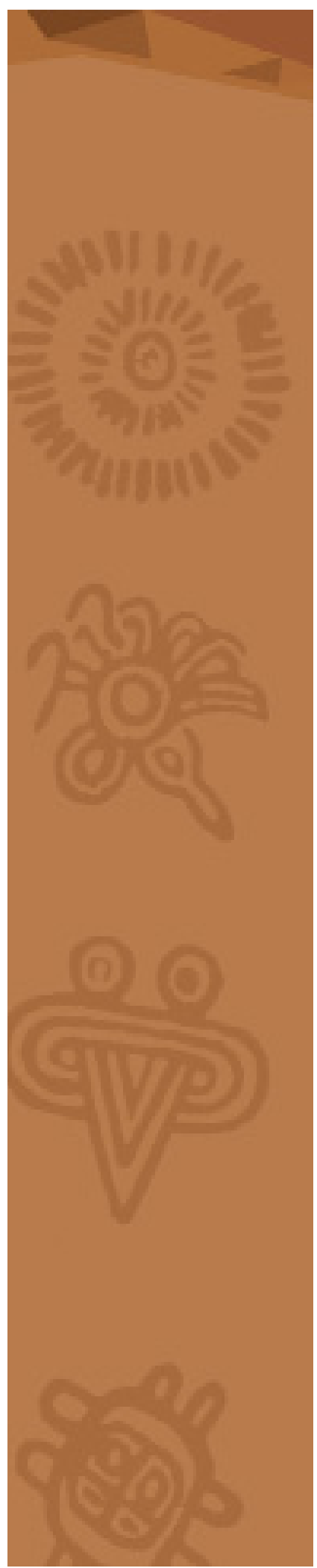

Aurell, J., \& Burke, P. (2013). De entresiglos a la década de los setenta: la reacción frente al positivismo .. En J. Aurell, C. Balmaceda, P. Burke , \& F. Soza, Comprender el pasado.Una historia de la escritura y el pensamiento histórico (págs. 237-286). Madrid: Ediciones Akal.

Barona, J. (1994). Ciencia e historia. Debates y tendencias en la historiografía de la ciencia. Godella: Seminari d'Estudis sobre la Ciencia- Universitat de València.

Benadiba, L. (2012). Historia Oral y Educación: Cuando los jóvenes se apropian del pasado. Revista del Programa de Investigaciones sobre Conflicto Social. Año 4(6), 190-195.

Benadiba, L., \& Plotinsky, D. (2005). Historia oral: construcción del archivo histórico escolar. Una herramienta para la enseñanza de las ciencias sociales. Buenos Aires: Ediciones Novedades Educativas.

Brunschwig, J., \& Lloyd, G. (2000). Diccionario Akal de El saber griego. Madrid: Ediciones Akal.

Coira, M. (2008). La construcción de la memoria: el pasado desde el presente en la trama dialógica de la entrevista. Los recuerdos de Angelo. En B. Favero, Voces y memoria de la inmigración: Mar del Plata en el siglo XX (págs. 19-34). Mar del Plata: Editorial de la Universidad Nacional de Mar del Plata.

de Garay, G. (1999). La entrevista de historia oral: ¿monólogo o conversación? Obtenido de Revista Electrónica de Investigación Educativa, 1 (1): http://redie.uabc.mx/vol1no1/contenido-garay.html

Educ.ar. (s/f). ¿Qué ventajas ofrece la historia oral en el aula? Obtenido de Educ.ar: https://www.educ.ar/dinamico/UnidadHtml_get_dbbcbc124b51-11e1-81f6-ed15e3c494af/index.html

François, É. (2006). En M. de Moraes, \& J. Amado, Usos e abusos da história oral. 8 Edición. Rio de Janeiro: Editora FGV.

Hernández, E. (2004). Tendencias historiográficas actuales. Escribir historia hoy. Madrid: Ediciones Akal.

James, D. (2004). Doña María: historia de vida, memoria e identidad política. Buenos Aires: Manantial.

Mayer, E. (1995). Los nuevos caminos de la historia oral en América Latina. Historia y fuente oral (13), 97-102. Obtenido de Historia y fuente oral (13).

Necoechea, G. (2000). Un experimento en historia pública e historia oral: los museos comunitarios de Oaxaca. En J. Aceves, Historia oral: ensayos y aportes de investigación : Seminario de Historia Oral y Enfoque Biográfico (págs. 65-80). México D.F.: CIESAS. 
Portelli, A. (2003). La orden ya fue ejecutada. Buenos Aires: Fondo de Cultura Económica.

Pozzi, P., \& Pérez, C. (2012). Historia oral e historia política: Izquierda y lucha armada en América Latina, 1960-1990. Santiago: LOM Ediciones.

Ramírez, R. (2010). Introducción teórica y práctica a la investigación histórica. Guía para historiar en las ciencias sociales. Medellín: Universidad Nacional de Colombia, sede Medellín.

Schwarzstein, D. (2001). Una introducción al uso de la historia oral en el aula. Buenos Aires: Fondo de Cultura Económica.

Scoufalos, C. (2007). 1955, memoria y resistencia. Buenos Aires: Biblos.

Sebe, J. C. (2000). Desafios para o história oral latinoamericana: o caso do Brasil. En M. de Moraes, T. Fernandes, \& V. Alberti, História oral. Desafios para o século XXI (págs. 85-98). Rio de Janeiro: Editoria Fiocruz-Casa de Oswaldo Cruz/CPDOC- Fundação Getulio Vargas.

Thompson, P. (1988). La voz del pasado: la historia oral. Valencia: Alfons el Magnànim.

Vannini, M. (2014). Políticas públicas de la memoria en Nicaragua. Obtenido de A Contracorriente. 12(1) 73-88: http://acontracorriente.chass.ncsu.edu/ index.php/acontracorriente/article/viewFile/1302/2225

\section{Walter Jerónimo Calderón Ramírez}

Licenciado en Comunicación Social por la Universidad Centroamericana (2003). Maestría en Políticas Sociales, Derechos y Protagonismo de Niños, Niñas y Adolescentes por la Universidad Centroamericana (2014). Maestría en Alta Gerencia en Administración Pública, Universidad Nicaragüense de Estudios Humanísticos, UNEH (2011). Ha realizado estudios en el Diplomado en Periodismo Moderno y Estrategias de Comunicación (2008) de la Universidad Hispanoamericana, Diplomado en Comunicación y Globalización, Universidad Hispanoamericana (2009); Diplomado en Afectividad, Equidad y Respeto en las Relaciones con la Niñez y la Adolescencia, UNAN-Managua (2008). De igual manera es graduado del Diplomado en Migraciones y Derechos Humanos realizado por el Programa de Naciones Unidas para el Desarrollo (PNUD) y la Universidad Centroamericana "José Simeón Cañas" de El Salvador (2009). El autor también es graduado del Posgrado en Investigación Periodística en la Universidad Centroamericana (2005) y Posgrado en Comunicación y Derechos de la Niñez (2003) en la Universidad Centroamericana. En la actualidad es Estudiante del Programa de Doctorado en Historia con mención en Estudios Regionales y Locales Transdisciplinarios de la Facultad de Humanidades y Ciencias Jurídicas de la UNAN-Managua. También se desarrolla como Docente titular y Coordinador de la Carrera de Comunicación para el Desarrollo de la Facultad de Humanidades y Ciencias Jurídicas de la UNAN-Managua. Este artículo se publica como parte de los compromisos académicos de dicho programa. 